\title{
LA NARRACIÓN TEATRAL ITALIANA ENTRE LENGUA Y DIALECTO
}

\author{
MARINA SANFILIPPO \\ UNED. Madrid \\ msanfilippo@flog.uned.es
}

\section{RESUMEN}

El problema de la situación lingüística del teatro italiano, condicionada durante siglos por la ausencia de un italiano hablado, sigue vigente en los albores del siglo XXI. En este trabajo se efectúa un estudio de las complejas relaciones entre lengua y dialecto en el habla teatral italiana de las últimas décadas, analizando las elecciones lingüísticas de varios intérpretes del Teatro di narrazione, una importante corriente del teatro italiano contemporáneo.

PALABRAS Clave: Teatro; narración oral; lengua; dialecto.

\section{SOMMARIO}

Il problema della situazione linguistica del teatro italiano, su cui ha pesato per secoli la mancanza di un italiano parlato, continua ad esistere agli inizi del secolo XXI. In questo lavoro si propone uno studio del difficile rapporto tra lingua e dialetto nel parlato teatrale italiano degli ultimi anni, analizzando le scelte linguistiche di diversi interpreti del Teatro di narrazione, un'importante corrente del teatro italiano contemporaneo.

PAROle ChIAVE: Teatro; narrazione orale; lingua; dialetto. 
A partir de finales de los años ochenta se ha difundido en Italia una modalidad teatral basada en la narración oral: autores como Marco Baliani', Marco Paolini ${ }^{2}$ o Laura Curino ${ }^{3}$, a los que en un segundo momento se han sumado los más jóvenes Ascanio Celesti$\mathrm{ni}^{4} \mathrm{o}$ Davide Enia ${ }^{5}$, han empezado a proponer espectáculos teatrales unipersonales, en los que, desde un escenario solitario y desnudo, desgranan monólogos narrativos que se caracterizan por estar expresados frecuentemente en un idioma que está más cerca del dialecto de origen del intérprete que de la lengua italiana ${ }^{6}$.

Los idiomas utilizados por este Teatro di narrazione $e^{7}$ ofrecen la posibilidad de aportar nuevas reflexiones sobre la difícil y compleja relación que existe entre la lengua y el teatro italianos. Esta relación tortuosa se debe a la peculiar historia lingüística italiana que ha hecho posible que, en Italia, en el ámbito de la expresión y la comunicación orales, el dialecto haya sido el vehículo lingüístico preferido, por lo menos hasta años muy recientes.

Recordemos que el italiano perteneció exclusivamente a la literatura durante largo tiempo: como escribió Tullio De Mauro en su fundamental Storia linguistica dell' Italia unita, «per secoli, l'italiana, unica fra le lingue nazionali europee moderne, e come poche altre lingue arioeuropee di cultura, ha vissuto soltanto o quasi soltanto come lingua di dotti» (De Mauro, 1965: 26). En efecto, la situación linguística italiana ha sido y sigue siendo muy diferente a la de España; baste pensar que en 1861, el año en que se proclamó el Reino de Italia, el porcentaje de italófonos no llegaba al diez por ciento ${ }^{8}$ (Grassi et alii, 1998: 243). En el siglo y medio escaso que nos separa de esa fecha, se ha actuado una auténtica italianización de Italia gracias, sobre todo, a la escuela y al servicio militar obligatorios, a las transformaciones sociales y económicas del país, a las migraciones internas que en los años Cincuenta y Sesenta del siglo $\mathrm{xx}$ afectaron a millones de italiano y a la difusión de los medios de comunicación, principalmente la televisión que hizo

1 Autor, actor y director teatral, fue uno de los creadores del Teatro Ragazzi en los años setenta. A partir de la mitad de los años ochenta, Baliani empezó a investigar las posibilidades pedagógicas y artísticas de la narración oral. Entre sus espectáculos de narración hay que mencionar Kohlhaas (1991), Corpo di Stato (1997) y Lo Straniero (2003).

2 Quizás el más conocido de los narradores teatrales. Entre sus espectáculos más representativos hay que recordar por lo menos la serie de los Album (cinco espectáculos de corte autobiográfico creados entre 1987 y 1999). Il racconto del Vajont (1993), e I TIGI, racconto per Ustica (2001).

${ }^{3}$ Autora y actriz teatral, miembro fundador del grupo Teatro Setrimo, una de las formaciones punteras del Teatro di Ricerca italiano en los años ochenta y noventa. Sus espectáculos más importantes como narradora son Stabat mater (1989), Passione (1991) y Olivetti. Camillo: alle radici di un sogno (1996).

4 Joven autor y actor teatral, muy apreciado por la crítica y el público. Es autor e intérprete de espectáculos como Radio clandestina. Roma, le fosse Ardeatine, la memoria (2000), Fabbrica (2002) y Scemo di guerra (2004).

5 Joven interprete teatral, conocido también por sus colaboraciones con Emma Dante. Su espectáculo más representativo es Italia-Brasile 3 a 2 (2002).

"A lo largo de este artículo voy a utilizar los términos lengua y dialecto aun consciente de la incertidumbre definitoria que caracteriza a estas dos palabras, puesto que es muy difícil dar de ellas una definición estrictamente linguiística y el estatuto de lengua depende de razones fundamentalmente políticas (Stussi, 1996: 4).

7 Desde hace algunos años la crítica especializada ha definido con este nombre a la actividad de los narradores y Laura Curino ha subrayado la importancia que ha tenido esta posición de la crítica puesto que «i critici hanno inventato la denominazione 'teatro di narrazione' conferendo uno statuto di esistenza a un tipo di lavoro teatrale che già esisteva, ma non aveva coscienza di costituire un genere» (Curino, carta no publicada). Más recientemente Gerardo Guccini ha propuesto también la definición de nuova performance epica (cf. el número 1/2004 de la revista Prove di drammaturgia).

* Se trata de un cálculo bastante optimista: según Tullio De Mauro, en realidad tan sólo el 2,5\% de la población italiana hablaba italiano en los años de la unificación nacional (De Mauro, 1965: 38). 
posible que la lengua italiana hablada se escuchara en las salas de estar de todo el país. Sin embargo es necesario tener en cuenta que, todavía en 1951, «per oltre quattro quinti della popolazione italiana il dialetto era ancora abituale e per quasi i due terzi [...] era l'idioma di uso normale nel parlare in ogni circostanza» (De Mauro, 1965: 106). En las décadas siguientes, es decir justo en la época de formación de la mayoría de los intérpretes del Teatro di narrazione ${ }^{9}$, se realizó una «italianizzazione selvaggia e approssimativa» (De Mauro, 1979: 49) que destruyó en parte el tejido lingüístico y cultural local, al que no se le atribuía ninguna relevancia ${ }^{10}$, pero permitió que le lengua italiana llegara a ser esa lengua viva e vera que Alessandro Manzoni echaba en falta en el siglo XIX.

En la actualidad, los italianos disponen por lo general de un repertorio linguístico asombrosamente amplio, con una fuerte polaridad entre lengua y dialecto. Según Francesco Sabatini (1990: 77) dicho repertorio está compuesto por dos variedades de italiano difundidas en todo el territorio nacional (italiano estándar e italiano de uso medio ${ }^{11}$ ) y cuatro variedades que, en cambio, se utilizan a nivel regional o local, como puede apreciarse en el esquema siguiente:

\begin{tabular}{|c|c|c|c|c|}
\hline \multirow[t]{2}{*}{$\begin{array}{c}\text { ASPECTOS } \\
\text { DIATÓPICOS }\end{array}$} & \multirow[t]{2}{*}{ VARIEDADES } & \multirow[t]{2}{*}{$\begin{array}{l}\text { ASPECTOS } \\
\text { DIAMESICI }\end{array}$} & \multicolumn{2}{|c|}{$\begin{array}{l}\text { ASPECTOS DIAFÁSICOS } \\
\text { Y DIASTRÁTICOS }\end{array}$} \\
\hline & & & Clases instruidas & Clases populares \\
\hline $\begin{array}{l}\text { Variedades } \\
\text { nacionales }\end{array}$ & $\begin{array}{l}\text { 1) italiano estándar } \\
\text { 2) italiano } \\
\text { de uso medio }\end{array}$ & $\begin{array}{l}\text { Escrito y } \\
\text { hablado-escrito } \\
\text { Hablado } \\
\text { y escrito }\end{array}$ & $\begin{array}{l}\text { Formal } \\
\text { Mediamente } \\
\text { formal e informal }\end{array}$ & - \\
\hline $\begin{array}{l}\text { Variedades } \\
\text { regionales } \\
\text { y locales }\end{array}$ & $\begin{array}{l}\text { 3) italiano regional } \\
\text { de las clases } \\
\text { instruidas } \\
\text { 4) italiano regional } \\
\text { de las clases } \\
\text { populares («italiano } \\
\text { popular») } \\
\text { 5) dialecto regional } \\
\text { o provincial } \\
\text { 6) dialecto local }\end{array}$ & $\begin{array}{l}\text { Hablado } \\
\text { Hablado } \\
\text { y escrito } \\
\text { Hablado } \\
\text { Hablado }\end{array}$ & $\begin{array}{l}\text { Informal } \\
- \\
\text { Informal } \\
\text { Informal }\end{array}$ & $\begin{array}{l}\text { - } \\
\text { uso unificado } \\
\text { con informalidad } \\
\text { más marcada } \\
\text { para el dialecto }\end{array}$ \\
\hline
\end{tabular}

9 Nacieron en la década de los cincuenta Roberto Anglisani, Marco Baliani, Laura Curino, Luigi Dadina, Marco Paolini, Giacomo Verde y Ombretta Zaglio, entre otros, mientras que en los años sesenta vieron la luz, por ejemplo, Lucilla Giagnoni y Enrico Messina. Por su parte, Ascanio Celestini y Davide Enia pertenecen ya a los años setenta.

${ }^{10}$ En 1972, Luigi Lombardi Satriani llamaba la atención sobre la cultura folclórica, que se estaba empobreciendo a causa del menor uso del dialecto, y, a contracorriente con respecto al clima de la época, afirmaba: «A mio parere, ritenere in ogni caso positiva la perdita del dialetto per l'acquisizione della lingua è posizione estremamente generica e acritica» (Lombardi Satriani, 1972: 17).

"Se trata de un tipo de italiano nacido del contacto entre el italiano estándar y los dialectos en la práctica de hablantes instruidos, que presenta características innnovativas e unitarias por lo que se refiere a los niveles morfosintáctico y léxico (Sabatini, 1990: 76-77). 
Además, los italianos, no sólo pueden escoger entre estas variedades, sino que, como ha puesto de manifiesto Gaetano Berruto (1993a y 1993b), tienen también la posibilidad de optar por una conducta lingüística que, como se verá más adelante, es bastante característica de los narradores teatrales: la alternancia y mezcla lingüística entre italiano y dialecto dentro de un mismo enunciado. Berruto (1993a: 32) considera que hay que incluir este «discorso multilingue» dentro del repertorio linguístico de los italianos, puesto que se trata de una opción expresiva bastante extendida y que, además, goza de cierta aceptación social ${ }^{12}$.

Conviene recordar que, como se apuntaba en el párrafo anterior, muchos de los actuales narradores teatrales han nacido en los años cincuenta y sesenta. Es decir han estudiado y se han formado en una época en la que el uso del dialecto estaba mal visto y la escuela y la televisión intentaban proponer un italiano medio que unificara linguísticamente la península. Por lo tanto, en esos años, la oralidad cotidiana de estos autores pudo haberse desarrollado de una forma bastante alejada del dialecto ${ }^{13}$; de hecho, Gabriele Vacis ${ }^{14}$, nacido en 1956, recuerda que sus padres y los de sus coetáneos

per ansia modernista, negli anni del boom economico pretendevano che parlassimo solo italiano, burlandosi degli zotici che si esprimevano in dialetto (Vacis, 2004: 61).

También Laura Curino recuerda que, en su familia, la única que le hablaba en dialecto era su abuela Primina ${ }^{15}$. Para ellos, por lo tanto, no existió un dilema sobre qué lengua escoger para expresarse en la vida cotidiana, pero la cuestión se presentó en relación con la lengua que iban a utilizar en el teatro ${ }^{16}$.

En efecto, es importante recordar también la situación lingüística del teatro italiano, puesto que, como ha subrayado Pietro Trifone, la ausencia de un italiano hablado ha condicionado durante siglos el destino y la difusión del teatro italiano:

la lingua della Commedia dantesca o del Decameron boccacciano, quanto a potenziale «teatralità», non ha nulla da invidiare all'inglese di Shakespeare o al francese di Molière; ma quella è divenuta la lingua della letteratura italiana, non è divenuta la lingua della società italiana. E il teatro, la più sociale delle arti, ha bisogno di una società di parlanti (Trifone, 2000: 19).

12 Sobre el code-switching y el code-mixing en el italiano hablado, cf. Grassi et alii (1998: 179-186).

13 Esto no dependía sólo de las características socioculturales de la familia de origen, sino, en gran medida, de la región italiana de residencia, puesto que, aún a mediados de los años setenta, el dialecto seguía siendo la única lengua de comunicación familiar en el cuarenta por ciento de los casos, aproximadamente, en el Sur y el Noreste de Italia (De Mauro, 1980: 7).

14 Director teatral que colabora frecuentemente con narradores. Como director del grupo Teatro Settimo apostó ya en los años ochenta por un teatro muy vinculado a la narración, dirigiendo espectáculos como Elementi di struttura del sentimento (1985), una adaptación de las Afinidades electivas de Goethe, en la que la historia era vista y narrada por las criadas, sin que los aristocráticos protagonistas aparecieran nunca en la escena.

${ }_{15}$ Conversación telefónica mantenida en septiembre de 2004.

16 Giovanni Tesio apunta hacia un fenómeno parecido con respecto a la producción poética en dialecto a partir de los años setenta: «non si parte dal dialetto per raggiungere la poesia, ma si scopre il dialetto mentre si cerca la poesian (Tesio, 1996: 81). 
Al no disponer de una lengua nacional hablada que pudiera servir de modelo para el habla teatral ${ }^{17}$, a lo largo de la historia, una gran parcela del teatro italiano se ha desarrollado en dialecto ${ }^{18}$ y esta tradición, que, en las últimas décadas del siglo XIX, hizo posible que la calidad artística del teatro dialectal fuera superior a la del teatro en lengua italiana (Paccagnella, 1994: 531), no perdió vitalidad en el siglo XX: en 1916 Antonio Gramsci asistía a espectáculos teatrales en dialecto piamontés y los reseñaba en el periódico Avanti, afirmando

il dialetto pone più rapidamente in contatto le due parti del teatro, le fa collaborare, suscita impressioni immediate, perché il linguaggio più proprio della maggioranza, mentre la lingua letteraria ha bisogno di una traduzione interiore che diminuisce la spontaneità della reazione fantastica, la freschezza della comprensione (citado por Franceschini, 1993: 36).

Sin embargo, el clima cultural de los años cincuenta-sesenta provocó en el teatro institucional cierto rechazo por el dialecto y éste último, hasta por lo menos los años ochenta, se vio limitado principalmente al cabaré y al teatro amateur ${ }^{19}$. De todas formas, a finales de los años noventa, Marco Martinelli, del grupo teatral de Le Albe, ha afirmado que

in Italia esiste un teatro dialettale molto diffuso. È un teatro fatto da dilettanti. Ha un forte valore sociale [...] D'altronde il teatro italiano è, per storia, un teatro dialettale. Dal ' 500 fino a Eduardo, i dialetti sono la spina dorsale della nostra drammaturgia. Nell' ambito del teatro di ricerca degli anni ' 80 , invece, era sicuramente strano e provocatorio usare i dialetti forse perché facevano pensare ai dilettanti o a una comicità di consumo. [Reivindica el legado cultural de Pasolini] Pasolini aveva insegnato che non dobbiamo arrenderci alla neutralità dell' italiano. E che il ricorso a una lingua che pare arcaica, quando invece è solo com-presente e sepolta, ha un valore eversivo (Guccini, 1998: 15).

Aunque el teatro de Pasolini está escrito en lengua italiana y no en dialecto, la lección del polémico intelectual friulano y su rechazo por el italiano estándar, está muy presente en varios narradores teatrales, así como el recuerdo del italiano teatral usado hacia la mitad de los años ochenta, que Vacis define como teatrese ${ }^{20}$. Siguiendo con las rememoraciones de Gabriele Vacis, el director recuerda que en 1985, cuando

nei teatri di ricerca si parlava come parlano i computer o meglio come si pensava che parlassero i computer quando erano ancora muti. E negli altri teatri si declamava

17 Puesto que, como indicaba ya Goldoni, el habla teatral es «una imitazione delle persone che parlano piu che di quelle che scrivono" (Goldoni, citado por Trifone, 2000: 74). Sobre la relación entre lengua hablada espontánea, lengua escrita y lengua hablada-recitada, es decir teatral, cf. Nencioni (1983).

18 Baste recordar que uno de los grandes autores teatrales italianos fue Angelo Beolco, Ruzante (Padua, 1502-1542), que escribió sus obras utilizando dialectos venetos y que la Commedia dell'arte, ese tipo de teatro cómico que Italia exportó a toda Europa, se caracterizó siempre por el plurilingüismo dialectal.

${ }^{19}$ Con algunas importantes excepciones, como Giovanni Testori (1923-1993) que, en su Trilogía degli Scarrozzanti, utiliza un pastiche linguístico en el que se mezclan italiano, lenguas extranjeras y dialectos lombardos.

${ }^{20}$ Según los recuerdos de este director, a principios de los años ochenta, hubo en su grupo un intento de utilizar el dialecto, pero no cuajo porque les parecía muy provinciano proponer ese tipo de idioma en el teatro: «quindi si tornava a lottare con la dizione italiana che, come capimmo solamente molti anni dopo, altro non era che un dialetto particolarissimo e pochissimo parlato dalle nostre parti: il teatrese» (Vacis, 2002: 17-18). 
stentoreamente ogni parola come se quella fosse l'ultima che un essere umano avrebbe pronunciato. [...] In questo quadro il dialetto arrivò [...] come una boccata d'aria fresca. Era fluido, suono che trascinava il gesto, parola che muoveva dal corpo dell'attore, che lo guidava a evocare mondi, che introduceva un sentimento del tempo apparentemente perduto (Vacis, 2002: 21-22).

Así que, a partir de este descubrimiento, en el Teatro di ricerca, el ámbito teatral del que proceden casi todos los narradores teatrales, se empieza a investigar sobre las posibilidades expresivas del dialecto y se aprovecha esa tendencia a mezclar dialecto y lengua que marca la obra de muchos hombres de teatro italianos, a partir del siglo XIX (de Viviani a Fo, pasando por Totò, Petrolini o Govi ${ }^{21}$ ). En este contexto de descubrimiento y experimentación, Marco Paolini empezó a investigar sobre las posibilidades expresivas del o de los dialectos vénetos ${ }^{22}$, aunque, como afirma el mismo Paolini, éstos tenían una connotación poco halagadora en el escenario teatral y en la pantalla de cine ${ }^{23}$. Las primeras obras de narración de Paolini son de corte autoficcional ${ }^{4}$ y en su investigación lingüística el autor, nacido en la ciudad véneta de Belluno, se inspiró en la novela de Vincenzo Meneghello, Libera nos a malo (1963), un texto lírico y laberíntico en el que el escritor reconstruye su niñez y adolescencia en Malo, un pequeño pueblo de la provincia de Vicenza, otra ciudad véneta como la Belluno de Paolini. Meneghello utiliza un lenguaje en el que la lengua italiana se entremezcla, de forma indisoluble, con el dialecto, ya que éste último es, para Meneghello, el único instrumento lingüístico que permite acceder a una especial esfera de la realidad.

Por lo que se refiere a Meneghello, su huella se deja notar también en otros narradores, que recurren a frases del escritor vicentino para explicar el papel del dialecto en sus narraciones: Laura Curino, por ejemplo, afirma que utiliza el idioma de su abuela porque, como Meneghello, considera «l'italiano come lingua per le ferite superficiali e il dialetto per le ferite profonde» (texto no publicado de Laura Curino). En un artículo, la narradora ha constatado también «in dialetto, scopro, posso dire cose che in italiano non avrei mai il coraggio di dire. Posso parlare dei sentimenti senza leziosità» (Curino, 1996: 16).

No sorprende que un código en el que se pueden expresar los sentimientos sin afectación o melindres sea vehículo de monólogos autobiográficos, como son muchas de las obras del teatro di narrazione. Franco Brevini, analizando la poesía neo-dialectal italiana, ha apuntado que, después de la desaparición del universo antropológico del dialecto, el momento autobiográfico representa un rasgo característico de los que utilizan el dialecto con fines artísticos, puesto que

21 Cf. Ferdinando Taviani (1995: 38-39).

${ }^{22}$ Sobre los distintas variedades de lengua y de dialectos vénetos utilizados por Paolini, cf. Marchiori (2003: 51-59).

23. «Nella commedia all'italiana, il veneto è la lingua delle servette e dei carabinieri. Nella Commedia dell'Arte, il dialetto veneto è la lingua dei servi; è la lingua bassa, anche nei contenuti» (Ponte di Pino, 2005, edición electrónica).

${ }^{24}$ En los primeros cuatro espectáculos que componen la serie de los Alhum, Paolini interpreta a su alter ego, Nicola, del que va narrando la infancia (Adriatico y Tiri in porta), la adolescencia (Aprile 74 e 5 ) y la juventud (Liberi tutti), mezclando datos autobiográficos propios con la creación de una autobiografía generacional (cf. Paolini y Ponte di Pino, 1999: 24-30 y Sanfilippo, 2003: 521-522). 
la poesia in dialetto tende alla rivendicazione d'un mondo perduto. Il dialetto diventa un idioletto «segnato», «macchiato», recante la traccia di una storia, individuale e collettiva [...] Il dialetto, che nel primo Novecento assolveva alla funzione di lingua interiore e assoluta, [...] si trasforma ora nel codice di una viva vicenda biografica, di una storia personale intrecciata a una vicenda sociale (Brevini, 1990: 29-30).

Además, según el crítico milanés, el dialecto se caracteriza, en la literatura más reciente, como «lingua dell'io e del suo microcosmo" (Brevini, 1990: 30). Los rasgos citados pueden rastrearse sin dificultad en muchos espectáculos de narración, como, por ejemplo, el monólogo Passione (Curino y et alii, 1998). En él Laura Curino utiliza una gran variedad de dialectos, a parte del suyo propio, el piamontés, que ocupa un lugar de honor en el cierre de la obra:

\section{le disse che domani le avrebbe insegnato a raccontare quella storia: \\ Con na vus cita cita, \\ vus di ninin chi sun ancura nen bon a parlà, \\ vus d'i parent ch'i ciaciaru, voci che chiacchierano, \\ la sera, prima di addormentarsi...}

Senza dimenticare neppure una parola:

qualcosa di semplice e perfetto che si chiama imparare

a

MEMORIA (Curino et alii, 1998: 71).

A parte la referencia a ese componente fundamental de la oralidad que es la memoria, aparece aquí la voz, indisolublemente ligada a una mezcla personal entre lengua y dialecto. Para Curino la palabra que narra historias parece encontrarse a medio camino entre la voz como sonido (la voz del niñito que no sabe hablar, las voces familiares que charlan en la oscuridad y que tienen esa corporeidad linguiística que, en Italia, sólo el dialecto puede ofrecer) y la memoria, sencilla y perfecta, una memoria dialectal y oral en la que ese «aprender de memoria» seguramente significa salvar la memoria de los hechos, más que repetir las palabras de un texto.

Curino estructura el monólogo en distintos fragmentos, en los que la mirada de la niña protagonista reconstruye la vida en Settimo Torinese ${ }^{25}$ en los años sesenta, cuando los inmigrantes, que llegaban, numerosos, de otras regiones de Italia, entremezclaban dialectos y costumbres. Por lo tanto, en Passione, Curino utiliza dialectos de media Italia e incluso nos presenta el italiano dudoso de una venezolana, que, después de asistir a un espectáculo de Dario Fo y Franca Rame ${ }^{26}$, afirma que «parlava en un dialecto tan antico,

${ }^{25}$ Se trata de una ciudad-dormitorio, que se encuentra a siete kilómetros de Turín y que a lo largo de los años cincuenta triplicó sus habitantes (pasando de 10.000 a 30.000 ) a causa de los inmigrantes que, desde el sur de Italia, llegaron ahí para trabajar en una fábrica de la Fiat.

${ }^{26} \mathrm{El}$ punto central de la obra es el descubrimiento del teatro por parte de la protagonista, mientras asistía a una representación del premio Nobel y su mujer, y su posterior passione por el mundo de la escena como posibilidad de evadirse de una realidad odiada y detestada. El homenaje a Dario Fo encuentra su explicación en el hecho de que este artista, con obras como Mistero Buffo, representa un punto de referencia obligado para los nuevos narradores teatrales. 
ma $\tan$ antico che lo capivo anche yo che no so l'italiano, figurarsi il dialetto" (Curino et alii, 1998: 59).

En efecto, si se quiere hablar de teatro, dialecto y narración hay que hacer referencia a esa koiné padana que Dario Fo utiliza en sus giullarate ${ }^{27}$. Para Fo «è una grande sfortuna per un attore non possedere un dialetto come fondo alla propria recitazione» (Fo, 1997b: 249), puesto que el dialecto es un idioma que no se lee en voz alta en el colegio y, en él, «le cadenze e i respiri, le parole, le costruzioni grammaticali sono autentiche, non c'è nulla di costruito» (Fo, 1997b: 249); no existe por lo tanto posibilidad de aplicar los manierismos linguísticos y fonéticos que caracterizan el teatro académico, alejándolo de la oralidad auténtica y cotidiana. Si el dialecto es, según Fo, una referencia fundamental para cualquier actor; es evidente que esto será especialmente importante para un actor-narrador que, por lo general, no interpreta a un personaje sino que habla desde sí mismo.

Dario Fo, por su parte no utiliza su dialecto de origen cuando narra sus juglaradas, sino que propone una lengua construida sobre distintos dialectos del norte de Italia, mezclados con idiomas medievales apócrifos, invenciones linguísticas típicas de la $\mathrm{Com}$ media dell'Arte y otras deformaciones que explotan aspectos cómicos del lenguaje. Se trata de un lenguaje que sin duda explora los territorios y las posibilidades de la oralidad popular ${ }^{28}$, pero que está vinculado

a uno dei poli della tradizione letteraria italiana, la cosiddetta «linea Folengo-Gadda ${ }^{29}$, il cui maggiore tratto distintivo risiede appunto nella scelta del pluringuismo. [...] Gli scrittori della linea Folengo-Gadda rifiutano i modelli linguistici dominanti e li rimpiazzano con idioletti artificiali ed eccentrici, elaborati mescolando insieme le componenti più diverse per tipologia d'uso, per provenienza geografica e per dislocazione temporale (Trifone, 2000: 151).

Los actuales narradores teatrales se inspiran, como Fo, en modelos de narrador popular, familiar o comunitario, por lo que el lenguaje que utilizan está muy vinculado al uso de lengua y dialecto en la sociedad italiana, pero al mismo tiempo estos autores, sin llegar a los niveles de manipulación y contaminación de lenguajes características del premio Nobel, emplean un tipo de expresión bastante alejado de lo natural y de lo espontáneo. Análogamente a los poetas dialectales italianos contemporáneos, el dialecto utilizado no coincide nunca con el que se habla realmente:

mancando o allentandosi il vincolo rappresentato dall'uso, il dialetto, divenuto sempre più codice personale, strumento di espressione della soggettività, viene adottato dal poeta con straordinaria libertà (Brevini: 1990: 67).

${ }^{27}$ A parte las historias que pertenecen a las distintas versiones de Mistero Buffo (cf. las dos cintas de vídeo publicadas en Fo, 1997a), se incluyen en esta categoría de espectáculo también Storia della tigre e altre storie (1979), La rava e la fava (1988), Johan Padan a la descoverta de le Americhe (1992), Lu Santo Jullare Francesco (1999), etc. La última creación de este tipo es Il tempio degli uomini liberi (2004), sobre la construcción de la catedral de Módena.

${ }^{28}$ No hay que olvidar que Dario Fo aprendió la mayoría de las técnicas narrativas y fabulatorias que utiliza en las juglaradas durante su infancia entre los pescadores del Lago Maggiore, la mayoría de los cuales eran narradores espontáneos o semiprofesionales (cf. Fo y Allegri, 1990: 18-36 y Soriani, 2005: 17).

${ }^{29}$ Teofilo Folengo, alias Merlin Cocai (Mantua, 1491 - Bassano, 1544), para sus poemas utilizó el maccheronico, una lengua de estructura latina pero con léxico italiano o italiano dialectal, que le permitió audaces investigaciones linguísticas. Carlo Gadda (Milán, 1893 - Roma, 1973), sus obras se caracterizan por un refinado pastiche linguístico en los que imbrinca léxicos especializados, usos jergales, italiano culto y dialectos. 
Un claro ejemplo es el neo-abruzo que el narrador Stefano Angelucci Marino mezcla con el italiano y con toques de inglés americano en su Trilogia della memoria ${ }^{30}$, dedicada al pueblo de Pizzoferrato (en la provincia de Chieti). El autor crea una lengua oral que no debe nada a la escritura, llena de invenciones y provocaciones lingǘsticas, en la que lo que importa es la búsqueda estilística y la espresividad.

En la obra de Ascanio Celestini, en cambio, encontramos una lengua más sobria, un idioma que no es dialecto ni italiano regional ${ }^{31}$, sino un italiano popular en el que el artista engarza palabras dialectales y términos romanos, que frecuentemente tienen un sabor anticuado o un valor de ruptura. Valga, como ejemplo de lo primero, la palabra pigione en lugar de affitto (alquiler), un término que suele encontrarse en boca de ciudadanos romanos nacidos treinta o cuarenta años antes que Celestini. En este aspecto, este joven Ascanio reproduce una tendencia al arcaísmo típica del italiano popular, como, por otra parte, utiliza otros rasgos de ese tipo de idioma, como la concordancia del nombre colectivo con un verbo en plural o el periodo hipotético de la irrealidad con doble potencial ${ }^{32}$. También conviene apuntar, para la tendencia de ruptura, el uso programático y reiterado del verbo imparare en aquellos casos en los que, en italiano standard, se utiliza el verbo insegnare; se trata de una forma muy difundida en el italiano popular romano y por lo tanto es capaz de connotar como romana toda una frase en perfecto italiano.

Desde el punto de vista de la pronunciación, Celestini no utiliza características típicas del romanesco, como puede ser el cricchiato o laringalizzazione $e^{33}$, y, en cambio, crea una musicalidad y una sonoridad muy personales, seguramente vinculadas con su labor de músico, a parte de intérprete teatral.

En fechas recientes planteé a varios narradores italianos la pregunta: «Italiano standard, italiano, regionale, dialetto, altre lingue. Quali codici usi quando narri? Perché?». Ascanio Celestini contestó afirmando que, en sus narraciones:

parlo usando la mia lingua parlata. Una lingua parlata a Roma, che è qualcosa di simile all'italiano. Parlo così perché voglio parlare con la mia lingua. Perché credo che nell'arte contemporanea l'artista debba essere presente nel mondo con la propria identità e non con un'identità fittizia, mediata dal personaggio.

Sin dudar de la sinceridad de Celestini, su lengua teatral no coincide exactamente con su habla cotidiana, como por otra parte le suele ocurrir a cualquier narrador ${ }^{34}, \sin$ embargo es importante su reivindicación de una identidad basada en el idiolecto de cada

${ }^{30}$ Integrada por Bruno la roccia (2000), Passaggio al bosco. Pizzoferrato '43/'44. Terra di nessuno (2002) y Valle del Sole Show (2003). Ha sido publicada en 2003 por el Ayuntamiento de Pizzoferrato y puede leerse en Intemet en la web de dramma.it.

" De todas formas, para el idioma utilizado por los habitantes de Roma, la distinción entre lo que se puede calificar como lengua y lo que en cambio pertenece al dialecto no es muy fácil, puesto que, desde el siglo XVI, el dialecto romanesco fue acercándose al habla toscana (cf. De Mauro, 1965: 26 y Serianni, 1996: 233).

${ }^{32}$ Sobre las características del italiano popular, cf. D'Achille (1994: 66).

${ }_{33}$ Sobre el cricchiato, cf. Canepari (1979: 20).

34 Como apuntó, ya en el siglo XIX, el folclorista Vittorio Imbriani que, en una nota a su recopilación de cuentos populares milaneses, La novellaja milanese, afirmó que, contando delante de un público, los narradores tendían a utilizar una forma áulica de su dettato y que «un poco il nobiliteranno sempre nel narrare, in Milano come a Napoli, come in Toscana e come in ogni altro luogo» (Imbriani, 1976: página sin numerar). 
uno. Encontramos el mismo tema en el narrador siciliano Davide Enia, que contestó de forma tajante: «Narro in un palermitano sporcato dall' italiano, perché è la lingua della mia culla, è il mio dialetto», añadiendo que el dialecto "possiede ritmi vari, diversi respiri e una pregnanza simbolica che l'italiano, per brevità di vita, non può possedere». Por un lado Enia se hace eco de las citadas convicciones de Dario Fo y por otro las amplía del campo de la pronunciación y del ritmo al campo semántico. También otro narrador que vive y trabaja en Italia, el judío búlgaro Moni Ovadia, desde su extranjería suavizada por toda una vida vivida en Italia, ha apuntado en la misma dirección que Enia, subrayando las posibilidades dramáticas e irónicas ofrecidas por los dialectos:

provo disagio verso l'italiano «puro", una lingua magnifica, ma che risente del limite di avere un 'identità nazionale troppo recente. Dal punto di vista sonoro e espressivo offre poco. Fenomeni come Dario Fo, Eduardo De Filippo o il palermitano Franco Scaldati non sarebbero esistiti in italiano. O Goldoni e Ruzzante. [...] [L'italiano] è una lingua morbida, dalla musicalità dolce, incantatrice ma, a mio parere, non inmediatamente teatrale. [...] in sé non possiede l'interiorità ironica e drammatica dei suoi dialetti e del suo volgare (Ovadia, 1998: 40).

De todas formas, el problema de selección del italiano o dialecto por parte de un narrador no es una novedad, sino que ha representado siempre una característica de la narración oral en Italia, en cualquier contexto que permitiera moverse dentro del bilingüismo. Como apunta el narrador siciliano Alberto Nicolino, el bilingüismo es un fenómeno típico de la narración tradicional de su región, en la que los dos idiomas pueden convivir dentro de un mismo cuento, como pasaba en las narraciones de los cuntist ${ }^{35}$, en las que los caballeros, al ser nobles, hablaban casi siempre en italiano, mientras que la narración en tercera persona y las voces de los personajes del pueblo eran en dialecto. La diglosia podía ser, además, aprovechada de forma alternativa: el dialecto para los cuentos cómicos y el italiano para las narraciones serias o edificantes. Estos fenómenos habían sido ya identificados por el famoso folclorista siciliano del siglo XIX, Giuseppe Pitré, aunque los ejemplos de pluringüismo

tendono a intensificarsi ed a farsi tanto più evidenti nelle fiabe raccolte più recentemente, in ambiti linguistico-culturali in cui il plurilinguismo sociale (e la sua consapevolezza) è molto più marcato di quanto non lo fosse nelle diverse culture regionali dell'Italia ottocentesca, quasi esclusivamente dialettofone (Lavinio, 1985: 42).

El pastiche lingüistico tenía que ser característico de los narradores ambulantes, que frecuentemente no compartían el dialecto de su público ocasional. En una investigación sobre narración oral en una zona de Toscana, Fabio Mugnaini (1985: 65) indica que, entre los narradores ocasionales que llegaban al lugar durante el invierno, en un pasado no muy lejano, se encontraban seggiolai (artesanos que construían o arreglaban sillas) del Friuli, una región del norte de Italia, con variedades lingüísticas muy distintas de los dialectos toscanos. El estudioso se centra en cuestiones de enriquecimiento del repertorio na-

${ }^{35}$ Narradores orales profesionales, muy difundidos en Sicilia en el siglo XIX, que utilizaban una técnica narrativa propia. Su repertorio estaba compuesto exclusivamente por historia de la épica carolingia. Cf. Di Palma (1991). 
rrativo local, gracias al contacto con narradores no residentes en la zona, y no dice nada sobre la lengua utilizada por los forasteros para comunicarse con su público toscano, pero es evidente que tendrían que recurrir a una mezcla de dialectos e italiano en pos de un código común con su auditorio.

Sin adentrarse ahora en la dinámica de los préstamos, contactos y cruces entre oralidad y escritura (o, más exactamente en el caso italiano, oralidad-dialecto y escritura-lengua italiana) es importante recordar que muchas veces, en las veladas de narración, el punto de partida de un cuento oral en dialecto podía ser un libro escrito en italiano ${ }^{36}$ y el narrador se encontraba jugando, automáticamente, con las posibilidades expresivas de los dos idiomas, tomando lo más eficaz de cada uno. Es un fenómeno que sigue vigente entre los narradores actuales, como puede apreciarse en las contestaciones que los narradores siguientes han dado a la pregunta «Italiano standard, italiano regionale, dialetto, altre lingue. Quali codici usi quando narri? Perché?»: Roberto Anglisani, «uso quello che mi serve per raccontare quello che voglio raccontare»; Emilio Franzina, «Alterno l'italiano colto al mio dialetto (il veneto) dove sia possibile, ad altri dove è necessario, con rare inserzioni di frasi o di parole straniere per facilitare e rendere più gradito l'ascolto»; Giacomo Verde, «Uso tutti i codici necessari a creare vicinanza con gli spettatori»; Ombretta Zaglio, «Se posso tutte le forme. Perché? Sono le varietà vive della lingua».

Para concluir, las elecciones lingüísticas y expresivas de los nuevos narradores italianos son un fiel reflejo de la situación y los repertorios lingüísticos de la Italia actual y, al mismo tiempo, son el resultado de una búsqueda estilística personal de cada uno.

\section{REFERENCIAS BIBLIOGRÁFICAS}

BEDUSCHI, Lidia (1982): «Atteggiamenti e ideologie della scrittura nei testi di tradizione orale». La ricerca folklorica $5,87-102$.

BERRUTO, Gaetano (1993a): «Le varietà del repertorio». En Introduzione all' italiano contemporaneo. La variazione e gli usi, de A. Sobrero (ed.), 3-36, Roma-Bari, Laterza.

- (1993b): «Varietà diamesiche, diastratiche, diafasiche». En Introduzione all' italiano contemporaneo. La variazione e gli usi, de A. Sobrero (ed.), 37-92, Roma-Bari, Laterza.

BrEvinI, Franco (1990): Le parole perdute. Dialetti e poesia nel nostro secolo, Turín, Einaudi.

CANEPARI, Luciano (1979): Introduzione alla fonetica, Turín, Einaudi.

CuRINO, Laura (1996): «La vicenda del testo». Prove di drammaturgia 1, 9-18.

CuRINO, Laura et alii (1998): Passione, Novara, Interlinea.

D'ACHille, Paolo (1994): «L'italiano dei semicolti». En Storia della lingua italiana, vol. II Scritto e parlato, de L. Serianni y P. Trifone (eds.), 41-79, Turín, Einaudi.

36 Cf. Sanga (1985). Aunque la tasa de analfabetismo en Italia en el 1871 era muy alta, Rudolph Schenda ha demostrado como ya en esa época eran frecuentes los casos de comunicación semioral o semiliteraria (Schenda, 1982:55). Guido di Palma recoge en su estudio varios testimonios sobre fabulatori-lettori, sin duda también traductores entre italiano y dialecto, en el siglo XIX en el sur de Italia (Di Palma, 1991: 36-38). Lidia Beduschi habla de narradoras que contaban las vidas de los santos, después de leerlas con anterioridad en libros, y cita también casos de lectura en voz alta, recordando que: «per questo tipo di lettura ad alta voce si può parlare quindi piuttosto di parafrasi che non di lettura vera e propria, nel senso che essa tende a un'esecuzione innovativa del testo scritto (il rapporto tra orale e scritto e sempre un rapporto di mediazione)», puesto que implicaba la traducción del italiano al dialecto (Beduschi, 1992: 91). Sobre intercanbios entre literatura culta y narrativa popular, cf., entre otros, Navarro Salazar (1982: 421). 
DE MAURo, Tullio (1965): Storia linguistica dell Italia unita, Bari, Laterza [1963].

- (1979): «Vicende linguistiche e teatro del Novecento». En L'Italia delle Italie. L'Italia, le regioni: le culture locali e le culture di base. Le molteplicita culturali nella tradizione italiana, 39-51, Florencia, Nuova Guaraldi.

- (1980): «Profilo linguistico della società italiana». En Lingua e dialetti nella cultura italiana da Dante a Gramsci, de T. De Mauro et alii, 7-21, Messina-Florencia, D'Anna.

Di PALMA, Guido (1991): La fascinazione della parola. Dalla narrazione orale al teatro: $i$ cuntastorie, Roma, Bulzoni Editore.

Fo, Dario (1997a): Mistero Buffo (libro y dos cintas de vídeo), Turín, Einaudi (1977).

- (1997b): Manuale minimo dell' attore, Turín: Einaudi (1987).

Fo, Dario y AlLEGRI, Luigi (1990): Dialogo provocatorio sul comico, il tragico, la follia e la ragione, Bari, Laterza.

FRANCESCHINI, Fabrizio (1993): «Dialetti e folclore nella scuola. Il lungo silenzio di Pisa. 'Fare vernacolo" o 'parlare dialetto'?». En Il vernacolo nell' attuale dibattito su tradizioni popolari, cultura del territorio e identità collettiva, de R. Ambrosini et alii, 33-68, Pisa, Tacchi.

GRASSI, Corrado et alii (1998): Fondamenti di dialettologia italiana, Roma - Bari, Laterza.

GuCCINI, Gerardo (1998): «Il pellegrinaggio continua. Conversazione con Marco Martinelli». Prove di Drammaturgia IV, 2, diciembre, 9-24.

IMBRIANI, V. (1976): La novellaja fiorentina con la novellaja milanese. Milán, Rizzoli (1871-1877).

LAVINIO, Cristina (1985): «Potenza e magia della fiaba. La fiaba tra i generi della prosa narrativa orale tradizionale». La ricerca folklorica $12,37-48$.

LOMBARDI SATRIANI, Luigi Maria (1972): «Dal dialetto alla lingua: ricatto culturale o perdita d'identità?». En Dal dialetto alla lingua. Atti del IX Convegno per gli Studi Dialettali Italiani, 5-18, [Pisa], Pacini.

MARCHIORI, Fernando (2003): Mappa Mondo. Il teatro di Marco Paolini. En Questo radichio non si toca, de M. Paolini (libro y cinta de vídeo), Turín, Einaudi.

MugnaINI, Fabio (1985): «《<...Da rraccontassi a vveglia $\gg$. Contesti e narratori nella tradizione orale». La ricerca folklorica $12,63-67$.

Navarro Salazar, M." Teresa (1982): “Dos versiones del mito de Polifemo: Roncal y Pisa». Cuadernos de Etnología y Etnografía de Navarra 39, enero-junio, 421-446.

NENCIONI, Giovanni (1983): «Parlato-parlato, parlato-scritto, parlato-recitato». En Di scritto e di parlato. Discorsi linguistici, 126-179, Bolonia, Zanichelli.

Ovadia, Moni (1998): Speriamo che tenga. Viaggio di un saltimbanco sospeso tra cielo e terra, Milán, Mondadori.

PacCagnella, Ivano (1994): «Uso letterario dei dialetti». En Storia della lingua italiana, vol. III. Le altre lingue, de L. Serianni y P. Trifone (eds.), 495-539, Turín, Einaudi.

PAolini, Marco y Ponte di Pino, Oliviero (1999): Quaderno del Vajont, Turín, Einaudi.

PONTE DI PINO, Oliviero (2005): «Come nascono le storie: album, appunti, racconti. Una conversazione con Marco Paolini». Ateatro 81 [ed. el. http://www.trax.it/olivieropdp/mostranotizie2.asp? num $=81$ \&ord $=49$ ].

SABATINI, Francesco (1990): «'Italiani regionali' e 'Italiano dell'uso medio'». En L'italiano regionale de M. A. Cortelazzo y A. M. Mioni (eds.), 75-78, Roma, Bulzoni.

SANFILIPPO, Marina (2003): «Narración autobiográfica en algunos autores del teatro italiano de los años noventam. En Teatro y memoria en la segunda mitad del siglo XX, José Romera Castillo (ed.), 519-526, Madrid, Visor Libros/UNED.

SANGA, Glauco (1985). «I generi della narrativa popolare italiana». La ricerca folklorica 12, 49-54.

SCHENDA, Rudolf (1982). «Canali e processi di circolazione della letteratura scritta e semiorale tra gli strati subalterni europei nel '700 e ' 800 ». En Oralità e scrittura nel sistema letterario, G. Cerina et alii (eds.), 49-61. Roma: Bulzoni. 
SerianNi, Luca (1996): «La letteratura dialettale romanesca». En Lingua e dialetto nella tradizione letteraria italiana, Atti del Convegno di Salerno, 5-6 novembre 1993, 233-253, Roma, Salerno Editrice.

SORIANI, Simone (2005): «In principio era Fo». Hystrio 1, 16-18.

STUSSI, Alfredo (1996): «Lingua e dialetto: teoria e storia». En Lingua e dialetto nella tradizione letteraria italiana, Atti del Convegno di Salemo, 5-6 novembre 1993, 3-28, Roma, Salerno Editrice.

TAVIANI, Ferdinando (1995): Uomini di scena uomini di libro. Introduzione alla letteratura teatrale italiana del Novecento, Bologna, il Mulino.

Tesio, Giovanni(1996): «La letteratura dialettale piemontese». En Lingua e dialetto nella tradizione letteraria italiana, Atti del Convegno di Salemo, 5-6 novembre 1993, 61-84, Roma, Salemo Editrice.

Trifone, Pietro (2000): L'italiano a teatro. Dalla Commedia rinascimentale a Dario Fo, PisaRoma, Istituti editoriali e poligrafici internazionali.

VACIS, Gabriele (2004): «Lettera a Marco Paolini». En Stabat mater. Viaggio alle fonti del 'teatro narrazione', de G. Guccini y M. Marelli (eds.), Castello di Serravalle, Le Ariette, 59-61.

- (2002): Awareness. Dieci giorni con Jerzy Grotowski, Milán, Rizzoli-Scuola Holden. 